\title{
A ENFERMAGEM NO CONTEXTO SOCIOPOLÍTICO E ECONÔMICO CONTEMPORÂNEO: ESTÍMULO AO EMPREENDEDORISMO PRIVADO E/OU FORTALECIMENTO DO EMPREENDEDORISMO SOCIAL?
}

\section{NURSING IN THE CONTEMPORARY SOCIO-POLITICAL AND ECONOMIC CONTEXT: ENCOURAGING PRIVATE ENTREPRENEURSHIP AND/OR STRENGTHENING OF SOCIAL ENTREPRENEURSHIP?}

\section{LA ENFERMERÍA EN EL CONTEXTO SOCIOPOLÍTICO Y ECONÓMICO CONTEMPORÁNEO: ESTÍMULO AL EMPRENDIMIENTO PRIVADO Y/O FORTALECIMIENTO DEL EMPRENDIMIENTO SOCIAL}

\author{
Alisson Fernandes Bolina ${ }^{1}$
}

A enfermagem é considerada uma prática social, cuja compreensão se dá pela inserção em um dado contexto sócio-histórico e político, no qual interfere e sofre interferência dele. Desde a implantação do Sistema Único de Saúde (SUS), a enfermagem vem se inserindo hegemonicamente no setor público e assumindo posição estratégica na organização do sistema de saúde, por ser considerada uma ciência de cuidado integral e integrador, capaz de assistir e gerenciar as práticas de cuidado e, sobretudo, de promover a saúde dos indivíduos, famílias e comunidades (BACKES et al., 2012).

Entretanto, a nova conjuntura sociopolítica e econômica ameaça em primeiro plano, a conquista de diversos direitos sociais e de saúde e, inevitavelmente, ecoa (rá) o ser e fazer enfermagem no Brasil enquanto prática social empreendedora para avanço das políticas públicas. Nesse contexto, podemos destacar algumas decisões mais recentes: desfinanciamento da saúde pelas medidas de austeridade introduzidas em 2016 (Emenda Constitucional 95); nova Política de Atenção Básica, publicada em 2017, que altera atribuições dos profissionais, limita ações, flexibiliza a carga horária de trabalho e retira profissionais da composição das equipes; e reforma trabalhista, que amplia a liberdade das empresas em determinar as condições de contratação, uso e remuneração dos trabalhadores, tendo em vista a redução de seus custos.

De maneira sucinta, podemos resumir que as medidas de austeridade (pelo modelo neoliberal de assistência à saúde), associadas à desregulamentação das leis trabalhistas, em meio à grave crise econômica, não só desconstituem a ideia de justiça social como infringem os princípios e diretrizes fundamentais de um sistema de saúde universal (CASTRO et al., 2019).

Neste contexto sociopolítico e econômico, o profissional de enfermagem vivencia uma inevitável insegurança. Ainda são desconhecidos os impactos dessas mudanças, porém estimase que o sucateamento do SUS e o estímulo à privatização da saúde comprometam a sustentabilidade hegemônica empregatícia do setor público de saúde, o que afetará substancialmente a participação da enfermagem, uma vez que corresponde a maior força de trabalho em saúde no Brasil.

\footnotetext{
Docente no Departamento de Enfermagem da Faculdade de Ciências da Saúde Universidade de Brasília - UnB. Doutor em Ciências pelo Programa de Pós-graduação em Enfermagem Fundamental da Escola de Enfermagem de Ribeirão Preto da Universidade de São Paulo (EERP-USP). Mestre em Atenção à Saúde pela Universidade Federal do Triângulo Mineiro. Enfermeiro graduado pela Universidade Federal do Triângulo Mineiro.
} 
A redução de direitos e de proteção social aos trabalhadores pode agravar ainda mais os desafios históricos em relação ao trabalho da enfermagem: extensa jornada de trabalho; vínculos empregatícios fragilizados; e discrepância salarial em relação aos demais profissionais de saúde, expressos por subjornadas, subsalários e subempregos. Atrelados a isso, podemos destacar também o elevado grau de insegurança e violência no ambiente de trabalho, a ausência de infraestrutura adequada para descanso e a falta de assistência, inclusive quando esses profissionais adoecem por condições de trabalho (MACHADO et al., 2016).

Neste cenário, o empreendedorismo privado, isto é, "ter o próprio negócio", emerge como a alternativa mais oportuna para os enfermeiros brasileiros. Nos Estados Unidos, onde o Sistema de Saúde baseia-se no Seguro Privado, essa prática já está bastante presente, sobretudo nas regiões em que os médicos não ofertam serviços à população (COPELLI et al., 2019). Seguindo essa tendência internacional, verifica-se no Brasil, nas últimas décadas, aumento de empresas registradas para atividade de enfermagem, o que, de maneira geral, está associado a constantes e crescentes insatisfações com as condições de trabalho supracitadas (ANDRADE et al., 2015).

O enfermeiro, na condição de profissional liberal, tem exercido suas atividades oferecendo diversos serviços de atenção à saúde: consultas de enfermagem à pacientes crônicos, gestantes e idosos; administração de medicamentos e tratamentos prescritos; orientações sobre a amamentação; e realização de curativos (ANDRADE et al., 2015; COPELLI et al., 2019). Em que se pese as contradições da relação público e privado, devemos assinalar que a maior parte dessas atividades é - ou pelo menos deveria ser - ofertada pelo SUS, que prevê em seu arcabouço legal atenção integral à saúde de todos os brasileiros.

Ao longo de mais de 30 anos de existência, o SUS tem se destacado como um espaço para o empreendedorismo social, por ampliar a atuação dos profissionais de saúde, especialmente dos enfermeiros, e mobilizar a comunidade por meio da participação social. Uma análise retrospectiva a respeito do envolvimento dos profissionais da saúde no SUS aponta para o reconhecimento de que o enfermeiro é o principal agente transformador das políticas e programas voltados para a saúde coletiva, principalmente da Estratégia Saúde da Família, visto que denota um olhar ampliado para as necessidades de saúde das famílias e comunidades (BACKES et al., 2012).

Enquanto empreendedores sociais, espera-se que os enfermeiros promovam mudanças das práticas normatizadas vigentes, com compromisso ético e político para consolidação dos princípios norteadores do SUS. Para tanto, denota-se a necessidade de que desenvolvam competências políticas, para atuar também em prol da conquista de condições dignas de trabalho, salários justos e, consequentemente, aumento da satisfação profissional.

Cabe mencionar que o empreendedorismo social na enfermagem está relacionado às características intrínsecas da profissão, para transformar a realidade social das comunidades; operar sobre os determinantes sociais e o avanço da equidade, com capacidade decisória de modificar as condições de saúde; mobilizar recursos comunitários; realizar gestão intersetorial; prover recursos para construção da profissão; criar uma rede de cooperação e cuidado; estabelecer contatos; e ter reconhecimento social, poder político e governabilidade no âmbito das comunidades, alicerçado à participação social.

São condutas e comprometimentos que precisam ser fortalecidos, sobretudo diante da atual conjuntura, com limites impostos nas esferas social, política e econômica. Portanto, faz-se necessário que a enfermagem balize o seu projeto político-legal, de forma a refletir criticamente sobre a relação do interesse público e coletivo em detrimento aos interesses econômicos e corporativos.

Diante do exposto, este texto objetiva provocar alguns questionamentos no sentido de refletir sobre qual(is) caminho(s) queremos trilhar para edificação da enfermagem brasileira: estimular o empreendedorismo privado em consonância com o modelo neoliberal de assistência 
à saúde que tem se instalado no Brasil? Ou fortalecer a profissão enquanto prática social empreendedora, capaz de modificar o "status quo", isto é, lutar pela melhoria das condições de trabalho e para a consolidação dos princípios norteadores do SUS? Podemos também refletir sobre a possibilidade de robustecer, nos espaços de formação, ambas as modalidades de empreendedorismo (privado e social) enquanto práticas complementares, sob a égide da relação público e privado imbricada no nosso Sistema de Saúde. São reflexões prementes, que precisam ser discutidas, pois sinalizam novos caminhos para a enfermagem.

\section{REFERÊNCIAS}

1. Andrade AC, Ben LWD, Sanna MC. Empreendedorismo na Enfermagem: panorama das empresas no Estado de São Paulo. Rev Bras Enferm. [Internet]. fev 2015 [citado em 01 ago 2019]; 68(1):40-44. Disponível em:

http://www.scielo.br/scielo.php?script=sci_arttext\&pid=S0034-

71672015000100040\&lng=en\&nrm=iso. doi: http://dx.doi.org/10.1590/00347167.2015680106p.

2. Backes DS, Backes MS, Erdmann AL, Büscher A. O papel profissional do enfermeiro no Sistema Único de Saúde: da saúde comunitária à estratégia de saúde da família. Ciênc Saúde Colet. [Internet]. jan 2012 [citado em 18 jul 2019]; 17(1):223- 30. Disponível em:

http://www.scielo.br/scielo.php?script=sci_abstract\&pid=S1413-

$81232012000100024 \& \operatorname{lng}=\mathrm{en} \& \mathrm{nrm}=\mathrm{iso} \& \operatorname{lng}=\mathrm{pt}$

3. Castro MC, Massuda AD, Almeida G, Menezes-Filho NA, Andrade MV, Noronha KVMS, et al. Brazil's unified health system: the first 30 years and prospects for the future. Lancet. 11 Jul 2019. Disponível em:

https://fgvsaude.fgv.br/sites/gvsaude.fgv.br/files/18t16929_atun_final.pdf. doi:

http://dx.doi.org/10.1016/S0140-6736(19)31243-7

4. Copelli FHS, Erdmann AL, Santos JLG. Entrepreneurship in nursing: an integrative literature review. Rev Bras Enferm. [Internet]. 2019 [citado em 18 jul 2019]; 72(Suppl 1):289-98. doi: http://dx.doi.org/10.1590/0034-7167-2017-0523

5. Machado MH, Santos MR, Oliveira E, Wermelinger M, Vieira M, Lemos W, et al. Condições de trabalho da enfermagem. Enferm Foco [Internet]. 2016 [citado em 18 jul 2019]; 7(Esp):63-76. Disponível em:

http://revista.cofen.gov.br/index.php/enfermagem/article/view/695/305 